JKEP

Vol 3, No 2, November 2018

ISSN: 2354-6042 (Print)

ISSN : 2354-6050 (Online)

\title{
Pengaruh Edukasi terhadap Self Eficacy Lansia dalam Mengatasi Nyeri Sendi dan Meningkatkan Mobilisasi
}

\author{
Pudjiati, Rosidawati, Mia Fatma Ekasari \\ Jurusan Keperawatan Poltekkes Kemenkes Jakarta III \\ Email:ati_wagiman@yahoo.co.id
}

\author{
Artikel history \\ Dikirim, Okt $10^{\text {th }}, 2018$ \\ Ditinjau, Okt $20^{\text {th }}, 2018$ \\ Diterima, Nov $6^{\text {th }}, 2018$
}

\begin{abstract}
Education is an effort to give informations which is expected to improve client's self efficacy that is able to change client's behavior to relieve joint pain faster. Furthermore, education that will be given to relieve joint pain and mobilization is warm compress and gymnastic for elderly. This research uses quasi-experiment with control group design as a method. This research intervenes gymnastic and warm compress for elderly. The sample of this research itself is the elderly who have mild to moderate joint pain through strategic sampling, purposive sampling and the sample size will use two different means test formula (Lemeshow, Holmer, Klar \& L Wanga, 2009). The sample in this research consists of two group, i.e., intervention group which has 40 people and control group which has 40 people. This research uses self-efficacy questionnaire for the elderly in relieving pain and improving mobilization. The result of this research uses bivariate hypothesis test that shows education of gymnastic for elderly and warm compress is more to affect the self-efficacy of the pain and mobilization.
\end{abstract}

Keywords: Education, self-efficacy; warm compress; gymnastic for elderly; joint pain.

\begin{abstract}
ABSTRAK
Edukasi merupakan suatu upaya untuk memberikan informasi yang diharapkan meningkatkan self effficacy klien sehingga bisa berubah perilaku klien dalam mempercepat penurunan rasa nyeri sendi.Adapun edukasi yang akan diberikan untuk mengatasi nyeri sendi dan mobilisasi adalah dengan kompres air hangat dan senam lansia. Metode penelitian menggunakan Quasi Eksperiment with control group design. Penelitian ini melakukan intervensi senam lansia dan kompres hangat pada lansia. Sampel adalah lansia yang memiliki riwayat nyeri ringan dan sedang, dengan strategi sampling Purposive
\end{abstract}


sampling dan besar sampel menggunakan formula uji beda dua mean (Lemeshow, Holmer, Klar \& L Wanga, 2009). Sampel penelitian terdiri dari dua kelompok yaitu kelompok intervensi berjumlah 40 orang, kelompok kontrol 40 orang, penelitian ini menggunakan kuesioner efikasi diri lansia dalam mengatasi nyeri dan kuesioner efikasi diri dalam meningkatkan mobilisasi. Hasil penelitian dilakukan uji hipotesis bivariate dengan hasil bahwa edukasi senam lansia dan pemberian kompres hangat lebih berpengaruh terhadap self efficacy rasa nyeri dan mobilisasi.

Kata Kunci: Edukasi, Self Efficacy; kompres hangat; senam lansia; nyeri sendi

\section{PENDAHULUAN}

Lansia atau Lanjut Usia merupakan kelompok yang rentan yang selalu ketergantungan dan menjadi beban tanggungan baik oleh keluarga, masyarakat, dan negara. Melihat kenyataan bahwa angka harapan hidup penduduk Indonesia yang ada dari tahun ke tahun semakin membaik, maka diperkirakan bahwa akan adanya jumlah lansia di Indonesia yang akan semakin meningkat pada tiap tahunnya (Muhajidullah, 2012)

Permasalahan yang sering terjadi pada lanjut usia diantaranya adanya gangguan gerak (immobilisasi), timbul ketidak stabilan mudah jatuh, gangguan mental, pikun (inteleqtual impairment), menyendiri (isolation), gangguan berkemih (inkotinensia urin), impoten (impotence), daya tahan tubuh menurun (immunodeficiency), infeksi, malnutrisi, susah buang air kecil, susah buang air besar, kesalahan minum obat (iartogenesis), susah tidur (Insomnia), fungsi indera menurun (impairment). Masalah-masalah tersebut merupakan beban bagi keluarga, masyarakat maupun negara (Maryam, 2008)

Nyeri pada pergerakan sendi (Artritis) dapat disebabkan oleh berbagai penyebab, salah satu yang dapat menimbulkan nyeri dan paling banyak dijumpai prevalensinya semakin meningkat karena berhubungan dengan bertambahnya usia adalah karena Osteoartritis. Osteoartritis merupakan penyakit sendi yang paling banyak dijumpai (60\%) dibandingkan dengan penyakit sendi lain seperti Arthritis Gout atau Arthritis Rheumatoid. WHO memperkirakan $40 \%$ populasi usia diatas 70 tahun menderita Osteoartritis dan $80 \%$ mengalami keterbatasan gerak (Sudoyo, 2006). Lansia yang mengalami 
nyeri jumlahnya mencapai $50 \%-60 \%$ karena Osteoartritis.

Terapi non farmakologi yang dapat digunakan yang dapat digunakan dalam menurunkan nyeri sendi antara lain: terapi konservatif mencakup penggunaan: latihan rentang gerak sendi, stimulasi dan massase kutaneus, terapi es dan panas, upaya mengistirahatkan sendi, transcutaneus electric nerve stimulation distraksi, teknik relaksasi, imajiunasi terbimbing, dan Hipnosis.

Upaya untuk dapat mengatasi rasa nyeri sendi pada lansia dengan beberapa tindakan non farmakologi di atas maka terlebih dulu diberikan Edukasi. Edukasi merupakan proses interatif yang mendorong terjadinya pembelajaran dan pembelajaran merupakan upaya penambahan pengetahuan baru, sikap keterampilan melalui penguatan praktik dan pengalaman tertentu (Smeltzer dan Bare, 2008: Potter \& Perry, 2016). Edukasi juga merupakan suatu upaya untuk memberikan informasi yang diharapkan meningkatkan self effficacy klien sehingga bisa berubah perilaku klien dalam mempercepat penurunan rasa nyeri sendi.

Menurut Bandura (1997) Self efficacy adalah belief atau keyakinan seseorang bahwa ia dapat menguasai situasi dan menghasilkan hasil (outcome) yang positif. Berdasarkan uraian di atas, kami tertarik melakukan penelitian tentang pengaruh edukasi terhadap self efficacy lansia dalam mengatasi nyeri sendi dan meningkatkan mobilisasi. Adapun tujuan penelitian diketahuinya pengaruh intervensi edukasi terhadap self efficacy dalam mengatasi rasa nyeri sendi dan meningkatkan mobilisasi.

\section{Tinjauan Pustaka}

Intolerasi aktifitas merupakan kondisi terjadinya penurunan kapasitas fisiologi seseorang untuk mempertahankan aktivitas sampai tingkat yang diinginkan (Somantri, 2007). Penyebab Immobisasi fisik menurut Stanley dan Beare (2002) ada 2 faktor penyebab immobilisasi: Faktor internal ( penurunan fungsi muskuloskeletal, perubahan fungsi neurologi, Nyeri, berkurangnya kemampuan kognitif, jatuh, perubahan hubungan social ) dan faktor eksternal 
(Program terapeutik, karakteristik dari penghuni mempengaruhi tingkat mobilitas, karakteristik dari staf perawatan yang mempengaruhi pola mobilitas.

Nyeri sendi adalah suatu peradangan sendi yang ditandai dengan pembengkakan sendi, warna kemerahan, panas, nyeri dan terjadinya gangguan gerak. Pada keadaan ini lansia sangat terganggu, apabila lebih dari satu sendi yang terserang ( Handono, 2013). Menurut teori tentang persepsi nyeri individu yang berbeda-beda dalam hal skala dan tingkatannya dijelaskan oleh Musrifatul dan Hidayat (2011), yang menyatakan bahwa nyeri merupakan kondisi berupa perasaan yang tidak menyenangkan.

Tolok ukur nyeri dapat menggunakan Numeric Rating Scale: Indikasi: digunakan pada pasien dewasa dan anak berusia > 9 tahun yang dapat menggunakan angka untuk melambangkan intensitas nyeri yang dirasakannya. Instruksi: pasien akan ditanya mengenai intensitas nyeri yang dirasakan dan dilambangkan dengan angka antara $0-10.0=$ tidak nyeri, $1-3$
$=$ nyeri ringan (sedikit mengganggu aktivitas sehari-hari), $4-6=$ nyeri sedang (gangguan nyata terhadap aktivitas sehari-hari), $7-10=$ nyeri berat (tidak dapat melakukan aktivitas sehari-hari).

New Oxford American Dictionary (2011) mendefinsikan efficacy sebagai kemampuan untuk memproduksi hasil yang diinginkan. Bandura (2001) mendefinisikan effikasi diri sebagai penilaian individu tentang kemampuan untk mencapai tujuan yang diinginkan. Bandura (dalam Delamater,2006) menyebutkan bahwa efikasi diri berfokus pada keyakinan individu bahwa dia bisa (atau tidak bisa) melakukan sebuah tindakan/perilaku spesifik secara efektif.. Miller (2009) menyebutkan individu dengan efikasi diri yang tinggi akan lebih gigih dalam keadaan dan situasi yang menantang, dan selalu berusaha untuk menguasai setiap permasalahan yang dia hadapi. Sebaliknya, individu dengan efikasi diri yang rendah akan lebih mudah menyerah dengan problema yang dihadapi.

Edukasi adalah penambahan pengetahuan dan kemampuan seseorang melalui teknik 
praktik belajar atau instruksi, dengan tujuan mengingat fakta atau kondisi nyata, dengan cara memberi dorongan terhadap pengarahan diri ( self direction) aktif memberikan informasi-informasi atau ide baru (Craven dan Hirnle dalam Suliha, 2002). Edukasi merupakan serangkaian upaya yang ditujukan untuk mempengaruhi orang lain, mulai dari individu, kelompok, keluaraga dan masyarakat agar terlaksananya perilaku hidup sehat (Setiawati, 2008)

Menurut Notoatmodjo (2007) pendidikan (edukasi) secara umum adalah segala upaya yang direncanakan untuk mempengaruhi orang lain baik individu, kelompok atau masyarakat, sehingga melakukan apa yang diharapkan oleh pendidik. Penyuluhan kesehatan atau pendidikan kesehatan merupakan upaya persuasi atau pembelajaran kepada masyarakat mau melakukan tindakan untuk memelihara dan meningkatkan kesehatannya (Stanhope \& Lancaster, 2004).

Untuk mengefektikkan upaya mengatasi nyeri sendi dengan diberikan terapi non farmakologik berupa latihan gerak sendi.
Terapi ini effektif pada lansia yang beririsiko mengalami Osteoartritis nyeri sendi ( Setyohadi \& Kushariyadi,2011). Terapi kompres hangat dan dingin dapat membantu menghilangkan nyeri, kekakuan dan pembengkakan pada sendi lutut. Untuk derajat nyeri yang cukup berat atau pada kasus yang terjadi secara kronik, mungkin terapi dingin dan panas tidak cukup untuk meredakan nyeri. Oleh karena itu, penting bagi Anda untuk mengkonsultasikannya pada dokter.

\section{METODE}

Jenis penelitian yang digunakan adalah penelitian Quasi Ekxperimental pre testpost test with control group design. Penelitian dilakukan dengan memberikan pre test pada kelompok kontrol dan kelompok intervensi, lalu kelompok intervensi diberikan edukasi tentang kompres hangat atau dingin, latihan gerak sendi. kemudian kelompok kontrol dan kelompok intervensi dilakukan post test. Penelitian ini dilaksanakan pada bulan Februari sd September 2018. Tempat yang digunakan adalah Panti Werdha Ciracas Jakarta Timur dan PSTW Budhi Dharma di Bekasi Timur. 
Sampel dalam penelitian ini adalah lansia yang tercatat pada dua panti lansia di wilayah Jakarta Timur dan Bekasi Timur dengan kriteria inklus: Lansia dengan usia $60-70$ tahun, bersedia menjadi responden, Lansia dapat berkomunikasi dengan baik, Lansia dengan riwayat nyeri sendi lutut. Sedangkan Kriteria Eksklusi: Responden tidak diikutkan bila skala nyeri berat

Strategi sampling menggunakan Purposive Sampling dengan besar sampel menggunakan formula pada satu populasi ( Lemeshow, Holmer, Klar \& L Wanga, 2009). Sampel dalam penelitian ini terdiri dari dua kelompok, yaitu kelompok eksperimen yang berjumlah 40 orang dan kelompok kontrol yang juga berjumlah 40 orang. kelompok eksperimen adalah kelompok yang diberikan kompres hangat atau dingin, latihan gerak sendi, sedangkan kelompok kontrol adalah kelompok yang mendapat tindakan sesuai prosedure di ruangan.

Dalam penelitian ini kami mengikut sertakan mahasiswa D III Keperawatan Poltekkes Kemenkes Jakarta III dan staf Panti Werdha Budhi Dharma Bekasi
Timur. Alat yang akan dipergunakan adalah Kuesioner tentang wawancara dengan gunakan tolok ukur nyeri menggunakan Numeric Rating Scale kuesioner data umum responden, lembar observasi. Untuk membuktikan hipotesis dalam penelitian ini, dilakukan uji statistik. Analisis data dalam penelitian ini meliputi : analisis univariat, analisis bivariat dan analisis multiuvariat.

\section{HASIL DAN PEMBAHASAN}

Karakteristik responden secara deskriptif seperti yang terlihat pada tabel 1 dan 2 . Sebagian besar responden pada kelompok intervensi adalah lansia lakilaki berusia 70.82 tahun, memiliki riwayat nyeri 38 orang lansia $(95 \%)$ dan skala nyeri pada skala 4 - 6. Sedangkan pada kelompok kontrol dapat disimpulkan bahwa sebagian besar responden adalah lansia laki-laki berusia 73.52 tahun memiliki riwayat nyeri 38 orang lansia (95\%) dan skala nyeri pada skala 1-3.

Hasil analisis menunjukkan ada perbedaan skala nyeri pada lansia antara kelompok intervensi dan kelompok kontrol, namun tidak ada perbedaan jenis 
kelamin dan riwayat nyeri pada kelompok intervensi dan kontrol.

Tabel 1

Distribusi karakteristik rdan kesetaraan esponden penelitian $(n=40)$

\begin{tabular}{ccccccc}
\hline \multirow{2}{*}{ Variabel } & kategori & \multicolumn{2}{c}{ Intervensi } & Kontrol & $\begin{array}{c}\text { p- } \\
\text { kesetaraan }\end{array}$ \\
\cline { 3 - 7 } & Laki-laki & 22 & 55 & 20 & 50 & 0.568 \\
\hline Jenis Kelamin & Jumlah & $\%$ & Jumlah & $\%$ & \\
& Perempuan & 18 & 45 & 20 & 50 & \\
\hline Skala Nyeri & Tdk nyeri & - & - & 2 & 5 & 0.000 \\
& $1-3$ & 2 & 5 & 30 & 75 & \\
& $4-6$ & 27 & 67.5 & 8 & 20 & \\
& $7-10$ & 11 & 27.5 & - & - & \\
\hline Riwayat Nyeri & Ya & 38 & 95 & 38 & 95 & 1.000 \\
& Tidak & 2 & 5 & 2 & 5 & \\
\hline
\end{tabular}

Hasil analisis pada tabel 2 menunjukkan bahwa tidak ada perbedaan usia antara kelompok intervensi dan kelompok kontrol.

Tabel 2.

Distribusi Karakteristik responden penelitian $(n=40)$

\begin{tabular}{ccccccccccc}
\hline Variabel & \multicolumn{3}{c}{ Intervensi } & & & Kontrol & & $\begin{array}{c}\text { p- } \\
\text { kesetar } \\
\text { aan }\end{array}$ \\
\cline { 2 - 11 } & Mean & $\begin{array}{c}\text { Me } \\
\text { dian }\end{array}$ & Min & Max & Mean & Median & Min & Max & \\
\cline { 2 - 11 } & 70.82 & $\begin{array}{c}69.5 \\
0\end{array}$ & 60 & 93 & 73.52 & 72 & 60 & 98 & 0,894 \\
\hline
\end{tabular}

WHO memperkirakan $40 \%$ populasi usia diatas 70 tahun menderita Osteoartritis dan 80\% mengalami keterbatasan gerak (Sudoyo, 2006). Umur seseorang menunjukkan tanda kemauan dan kemampuan, ataupun bagaimana seseorang bereaksi terhadap ketidakmampuan melaksanakan aktifitas sehari-hari (Potter, 2008). Seseorang dengan usia 70 tahun mungkin dapat memiliki usia fisiologis seperti usia 50 tahun atau sebaliknya, seseorang dengan usia 50 tahun mungkin memiliki banyak penyakit kronis (Pudjiastuti, 
2003). Nyeri sendi adalah masalah bagi pasien dalam semua kelompok usia yang menyerang persendian seseorang (Stanley, 2007).

Penelitian ini tidak sesuai dengan hasil penelitian Ani Dwi Pratintya dkk (2014) menyatakan bahwa karakterisitik responden berdasarkan jenis kelamin diketahui bahwa lanjut usia yang mengalami nyeri sendi paling banyak berjenis kelamin perempuan sebanyak 83,3\%, sedangkan laki-laki 16,7\%. Hal ini juga tidak sesuai dengan hasil penelitian Hadi Masyhurrosyidi dkk (2012) yang menyatakan bahwa sebagian responden wanita $(85 \%)$ dengan usia $55-70$ tahun $(80 \%)$, dengan skala nyeri $=8$. Namun penelitian ini didukung oleh Mc Caffery dan Passero (1999) dalam Andarmoyo (2013) secara umum pria dan wanita tidak berbeda secara makna dalam berespon terhadap Nyeri. Beberapa kebudayaan mempengaruhi jenis kelamin dalam memaknai nyeri (misal: menganggap bahwa seseorang laki-laki harus berani dantidak boleh menangis, sedangk anak perempuan boleh menangis dalam situasi yang sama. Selain itu faktor yang mempengaruhi nyeri sendi antara lain umur, jenis kelamin, suku bangsa, genetik, kegemukan dan penyakit metabolik, kelainan pertumbuhan, cedera sendi, olah raga dan pekerjaan (Tjokronegoro, 2004).

\section{Perbedaan skor self efficacy terhadap nyeri sendi dan mobilisasi pada lansia sebelum dan sesudah intervensi pada kelompok intervensi dan kontrol}

Hasil analisis bivariat pada tabel 3, menunjukkan terdapat perbedaan bermakna skor self efficacy terhadap nyeri dan mobilisasi pada kelompok intervensi sebelum dan sesudah intervensi edukasi (nilai $\mathrm{p}=0,000$ ), dan selisih nilai rata-rata peningkatan skor self efficacy terhadap nyeri pada kelompok intervensi lebih besar (nilai selisih $=6.400$ ) sedangkan pada kelompok kontrol rata-rata selisih skor sebesar 0.845 , begitu juga selisih nilai rata-rata skor self efficacy dalam mobilisasi pada kelompok intervensi lebih besar (nilai selisih $=6.332$ ) sedangkan pada kelompok kontrol rata-rata selisih sebesar 0.872 . 
Tabel 3.

Analisis skor self efficacy terhadap nyeri sendi dan mobilisasi pada lansia sebelum dan sesudah intervensi edukasi tentang nyeri sendi, pemberian kompres hangat, mobilisasi, senam lansia

\begin{tabular}{|c|c|c|c|c|c|c|}
\hline Variabel & Kelompok & Mean & SD & $95 \% \mathrm{CI}$ & $\mathrm{T}$ & p-value \\
\hline Skor self & Kel. Intervensi & & & & & \\
\hline efficacy & Sebelum & 79.56 & 19.757 & $-80.121--67.483$ & -23.625 & 0.000 \\
\hline \multirow[t]{6}{*}{ thd nyeri } & Sesudah & 83.36 & & & & \\
\hline & Selisih & -6.400 & & & & \\
\hline & Kel. Kontrol & & & & & \\
\hline & Sebelum & 75.75 & 2.960 & $0.705-2.599$ & 3.530 & 0.081 \\
\hline & Sesudah & 74.10 & & & & \\
\hline & Selisih & 0.845 & & & & \\
\hline Skor self & Kel. Intervensi & & & & & \\
\hline efficacy & Sebelum & 75.29 & 6.629 & $-8.452--4.212$ & -6.041 & 0.000 \\
\hline \multirow[t]{6}{*}{ mobilitas } & Sesudah & 81.63 & & & & \\
\hline & Selisih & -6.332 & & & & \\
\hline & Kel. Kontrol & & & & & \\
\hline & Sebelum & 74.13 & 11.185 & $-0.657-6.497$ & 1.651 & 0.071 \\
\hline & Sesudah & 73.21 & & & & \\
\hline & Selisih & 0.872 & & & & \\
\hline
\end{tabular}

Upaya untuk mengatasi nyeri sendi pada lansia dapat dilakukan dengan tindakan non farmakologi seperti latihan fisik, terapi es dan panas dll. Pemberian kompres hangat pada bagian nyeri sendi lutut dilakukan oleh peneliti selama 20 menit dan diberikan selama 2 minggu dilakukan 2 ( dua ) kali dalam seminggu yaitu hari Selasa dan Jum"at. Hal ini sesuai dengan penelitian Ani Dwi
Pratintya, Harmilah, Subroto (2014) yang menyatakan bahwa kompres hangat menurunkan nyeri sendi pada lansia. Proses vasodilatasi yang terjadi saat pemberian kompres hangat dapat melebarkan $\mathrm{p}$ buluh darah sehingga dapat meningkatkan aliran darah pada bagian yang nyeri. Kompres hangat juga dapat meninggalkan relaksasi otot serta mengurangi rasa nyeri akibat spasme dan 
kekakuan (Potter \& Perry, 2005). Panas bekerja dengan cara menstimulasi reseptor nyeri untuk memblok reseptor nyeri (Muttaqin, 2008 ). Penelitian tentang pengaruh kom pres hangat terhadap nyeri pada lanjut usia dengan Osteoarthritis telah dilakukan oleh Andrea (2002) di Rumah Sakit Rehabilitasi Medik Semarang untuk mendapatkan efek analgetik dan relaksasi otot untuk mengontrol dan mengatasi nyeri.

Salah satu latihan fisik yang dianjurkan pada lansia adalah senam lansia. Senam Lansia dapat memberikan pengaruh yang baik bagi kesehatan tubuh lansia salah satunya melatih kemampuan otot sendi pada lansia agar tidak terjadi kekakuan sendi ( Martono, 2009). Maryam (2008), mengemukakan bahwa latihan fisik akan bermanfaat untuk meningkatkan kesegaran jasmani pada lansia jika dilaksanakan dalam zona latihan paling sedikit 15 menit. Frekuensi latihan yang tepat untuk memperbaiki dan mempertahankan kesegaran jasmani adalah dilakukan paling sedikit tiga hari atau sebanyakbanyaknya 5 hari dalam satu minggu
Senam lansia dilakukan oleh lansia dibimbing oleh peneliti memiliki durasi minimal 30 menit Dan diberikan selama 2 minggu dilakukan 2 kali dalam seminggu yaitu hari Selasa dan Jum'at. Hal ini memberikan pengaruh yang berarti bagi kebugaran lansia sehingga lansia akan menjadi lebih aktif yang secara otomatis akan meningkatkan kemandirian lansia dalam pemenuhan mobilisasi. Senam lansia merupakan salah satu jenis olah raga yang cocok dan dapat dilakukan oleh lansia (Nugroho, 2008). Senam lansia merupakan bagian dari dari latihan fisik. Latihan fisik adalah segala upaya yang dilaksanakan untuk meningkatkan kebugaran jasmani dan kondisi fisik lansia (Pudjiastuti, 2003). Hal ini sesuai dengan hasil penelitian Diah Kristiana dan Dian Prawesti (2013) bahwa senam lansia dapat menurunkan nyeri sendi pada lansia. Berdasarkan hal tersebut asumsi peneliti lansia dapat melakukan aktivitas ( mobilisasi ).

Dalam penelitian Theresia, Titin, Marlina ( 2015 ) aktivitas yang dilakukan responden antara lain: jalan kaki, senam, yoga, renang.Aktivitas-aktivitas tersebut 
lebih banyak menggunakan sendi lutut sehingga memberi pengaruh terhadap penurunan nyeri. Penelitian menunjukkan bahwa dengan melakukan latihan fisik, serta melalui pendidikan kesehatan untuk meningkatkan status kesehatan sangat berpengaruh terhadap angka penurunan kekambuhan Arthritis

\section{Perbedaan skor self efficacy terhadap rasa nyeri dan mobilisasi antar kelompok.}

Tabel 4 menggambarkan Perbedaan skor self efficacy terhadap rasa nyeri dan mobilisasi sesudah intervensi edukasi antar kelompok

(Julie, 2006, Bredland et al,2011).

Tabel 4.

Perbedaan skor self efficacy terhadap rasa nyeri dan mobilisasi sesudah intervensi edukasi antar kelompok

\begin{tabular}{lllllccc}
\hline \multicolumn{1}{c}{ Variabel } & Kelompok & $\mathrm{N}$ & Mean & SD & $95 \%$ CI & F & P value \\
& & & & & & & \\
Self $\quad$ efficacy & Intervensi & 40 & -6.400 & 6.960 & $-9.591--4.898$ & 12.759 & 0,000 \\
nyeri & Kontrol & 40 & 0.845 & 2.465 & & & \\
Self efficacy & Intervensi & 40 & -6.332 & 6.629 & $-9.487--4.922$ & 3.982 & 0.000 \\
mobilisasi & Kontrol & 40 & 0.872 & 2.797 & & & \\
\hline
\end{tabular}

Hasil analisis menunjukkan bahwa terdapat perbedaan skor self efficacy terhadap rasa nyeri dan mobilisasi ( $\mathrm{p}=$ 0.000 ) antara kelompok intervensi dan kelompok kontrol setelah dilakukan intervensi edukasi tentang nyeri sendi, pemberian kompres hangat, mobilisasi, senam lansia.

Edukasi tentang nyeri sendi, pemberian kompres hangat, imobilisasi, senam lansia sangat efektif dalam meningkatkan self efficacy. Menurut Bandura dalam Mustaqim (2011) bahwa perkembangan self efficacy dalam tiap fase perkembangan dibutuhkan kompetensi dari individu.Meskipun tahap perkembangan yang dilalui individu tidak sama.sesuai tumbuh kembang, usia, pengalaman dan perluasan lingkungan. Pada masa lanjut usia, efikasi diri berfokus pada penerimaan dan penolakan terhadap kemampuannya, seiring dengan penurunan kondisi fisik dan 
intelektualnya. Masalah kesehatan yang sering terjadi pada lansia berbeda dari orang dewasa, yang menurut Kane dan Ouslander sering disebut dengan istilah 14 diantaranya : immobility( kurang bergerak ) instability ( berdiri dan berjalan tidak stabil atau mudah jatuh ), incontinence (beser buang air kecil dan atau buang air besar ), intellectual impairment (gangguan intelektual/ dementia).

Penyuluhan kesehatan atau pendidikan kesehatan merupakan upaya persuasi atau pembelajaran kepada masyarakat mau melakukan tindakan untuk memelihara dan meningkatkan kesehatannya (Stanhope \& Lancaster, 2004).Kegiatan penyuluhan ini diharapkan lansia dapat memahami proses menua, pengenalan nyeri sendi dan perawatannya. Untuk mengefektifkan upaya mengatasi nyeri sendi dengan diberikan terapi non farmakologik berupa latihan gerak sendi.Terapi ini effektif pada lansia yang beririsiko mengalami Osteoartritis nyeri sendi (Setyohadi \& Kushariyadi, 2011). Terapi kompres hangat dan dingin dapat membantu menghilangkan nyeri, kekakuan dan pembengkakan pada sendi lutut.

Edukasi merupakan serangkaian upaya yang ditujukan untuk mempengaruhi orang lain, mulai dari individu, kelompok, keluarga dan masyarakat agar terlaksananya perilaku hidup sehat (Setiawati, 2008 ), Tujuan edukasi untuk mengubah pemahaman individu, kelompok dan masyarakat di bidang kesehatan agar menjadikan kesehatan sebagai sesuatu yang bernilai, mandiri dalam mencapai tujuan hidup sehat serta dapat menggunakan fasilitas pelayanan kesehatan yang ada dengan tepat dan sesuai (Suliha, 2002). Hasil penelitian ini sesuai Aria Wahyuni dan Fitrianola R ( 2015 ) yang menyatakan bahwa edukasi kesehatan efektif untuk meningkatkan self efficacy.

Penelitian Dwidiyanti (2015) menyatakan bahwa efikasi diri merupakan sesuatu hal dapat memandu kemandirian pasien menjadi meningkat.Kemandirian pasien ada tingkatannya mulai dari tidak bisa, mau belajar, sering diingatkan, jarang diingatkan dan mandiri perubahan atau tindakan pemeliharaan dan peningkatan 
kesehatan yang dihasilkan oleh pendidikan kesehatan ini didasarkan pengetahuan dan kesadarannya melalui proses pembelajaran sehingga perilaku tersebut diharapkan akan berlangsung lama ( long lasting) dan menetap (langgeng) karena didasari oleh kesadaran (Arini, 2012)

\section{SIMPULAN}

Berdasarkan hasil penelitian dapat disimpulkan sbb: Sebagian besar responden lansia baik pada kelompok kontrol maupun kelompok intervensi berjenis kelamin laki-laki dengan usia 70 tahun keatas. Namun skala nyeri yang dialami kelompok intervensi sekitar 4-6, sedangkan kelompok kontrol skala nyeri 1-3. Terdapat perbedaan bermakna self efficacy terhadap nyeri pada kelompok intervensi sebelum dan sesudah edukasi ( nilai $\mathrm{p}=0.000$ ) dengan selisih nilai ratarata skor sebesar 6.400, sedangkan pada kelompok kontrol rata-rata selisih skor sebesar 0.84. Terdapat perbedaan bermakna self efficacy terhadap mobilisasi pada kelompok intervensi sebelum dan sesudah edukasi ( nilai $\mathrm{p}=$ 0.000) dengan selisih nilai rata-rata skor sebesar 6.333, sedangkan pada kelompok kontrol rata- rata selisih skor sebesar 0.873. Hasil analisis terakhir menunjukkan bahwa ada perbedaan bermakna skor self efficacy terhadap rasa nyeri dan mobilisasi $(\mathrm{p}=0.000)$ antara kelompok intervensi dan kelompok kontrol setelah di lakukan intervensi edukasi tentang : nyeri sendi, pemberian kompres hangat, imobilisasi, senam lansia. Berdasarkan hal di atas bahwa Edukasi tentang nyeri sendi, pemberian kompres hangat, imobilisasi, senam lansia sangat efektif dalam meningkatkan self efficacy pada lansia. Senam lansia dan kompres hangat dapat diterapkan dalam memberikan pelayanan kesehatan. Sehingga menumbuhkan self efficacy lansia untuk melakukan senam lansia dan kompres hangat secara mandiri untuk mengurangi rasa nyeri dan peningkatan mobilisasi.

\section{UCAPAN TERIMA KASIH}

Pelaksanaan penelitian ini banyak menerima bantuan dan bimbingan dari berbagai pihak, maka perkenankanlah kami mengucapkan banyak terima kasih kepada yang terhormat: Tim Pembina Risbinakes beserta jajarannya, Tim Pakar, Direktur Poltekkes Kemenkes Jakarta III 
beserta jajarannya, Tim Kaji Etik

Poltekkes Kemenkes Jakarta III, Kepala

PSTW Budhi Dharma Bekasi Timur

beserta jajarannya. Sebagai penutup kami mengharapkan kelanjutan kegiatan penelitian ini serta mengharap kritik dan saran yang bersifat membangun.

\section{DAFTAR RUJUKAN}

Arini. 2012. "Hubungan umur dan tingkat pendidikan terhadap pemberian ASI eksklusif". http;//aperlindraha.ward press.com

Bandura, A. 2001.Self Efficacy in Changing Societies. New York: Cambridge University Press

Chiou, WB \& Wan CS .2007. The dynamic change of Self Efficacy in information searching on the Internet: Influence of valence of Experience and prior Self Efficacy. The Journal of Psychology.

Delamater, J. 2006. Handbook of Social Psychology. New York: Spinger

Depkes RI. 2008. Pedoman Pembinaan Kesehatan Usia Lanjut Bagi Petugas Kesehatan. Jakarta : Depkes.

Lemeshow S, Hosmer DW, Klar J, Lwangsa SK. 2009. Adequasi of sample size in Health Studies, Edisi terjemahan. Yogyakarta: Gajah Mada University Press.
Mariyo. 200".8. Pelayanan Kesejahteraan Sosial lanjut usia (online), (http/bp.depsos.go.id), diakses 8 November 2011

Maryam. 2008. Mengenal usia lanjut dan perawatannya. Salemba Medika: Jakarta

Masyhurrosyidi Hadi. 2012. Pengaruh kompres hangat rebuasan jahe terhadap tingkat nyeri sub akut dan kronis pada lansia dengan Osteoartritis lutut di Puskesmas Arjuna Kecamatan Klojan Malang. Jawa Timur.

Miller,SM. 2009. The measurement of Self Efficacy in persons with Spinal Cord Injury: Psychometric Validation of The Moorong Self Efficacy Scale. Disability and Rehabilitation

Muhajidullah, K. 2012. Keperawatan geriatrik: Merawat lansia dengan cinta dan kasih sayang. Yogyakarta: Pustaka Pelajar

Muttaqin. 2008. Asuhan keperawatan klien dengan gangguan system persyarafan. Salemba Medika: Jakarta

Muttaqin. A. 2010. Pengkajian keperawatan aplikasi pada praktek klinik. Salemba Medika: Jakarta

Notoatmodjo,S. 2007. Promosi Kesehatan dan Ilmu Perilaku. Jakarta: Rineka Cipta

Nugroho. 2000. Keperawatan Gerontik. EGC: Jakarta 
Potter \& Perry. 2005. Buku Ajar Fundamental Keperawatan. Volume 2. EGC: Jakarta

Price S.A \& Wilson L.M. 2005. Patofisiologi: Konsep Klinik Proses-proses Penyakit. Jakarta: EGC

Pudjiastuti. 2003. Fisioterapi pada lansia. Jakarta: EGC

Potter \& Perry. 2005. Buku Ajar Fundamental Keperawatan" Volume 2. EGC: Jakarta

Smeltzer, Sc, Bare Brenda $G$ et all (2008). Brunner \& Suddarth Textbook of Medical Surgical Nursing. Eleventh Edition. Vol 2. Lippincott Williams \& Wilkins. Philadelphia
Stanley, M \& Beare, P.G. (2006) Buku Ajar Keperawatan Gerontik. (Nety Juniarti \& Sari Kurnianingsih, Penerjemah). Edisi ke 2. Jakarta:EGC

Sudoyo. 2006. Ilmu penyakit dalam jilid III. Departemen Ilmu Penyakit Dalam Fakultas Kedokteran Universitas Indonesia: Jakarta. 